\title{
Produção de cultivares de Anthurium andraeanum \\ nas condições de Acorizal-MT ${ }^{(1)}$
}

\author{
CARMEN LUCIA FERREIRA FAVA ${ }^{(2)}$, ELISANGELA CLARETE CAMILI (3)
}

\begin{abstract}
RESUMO
O cultivo de flores tropicais constitui um nicho de mercado a ser explorado no estado de Mato Grosso. O objetivo deste trabalho foi avaliar a produção de sete cultivares de antúrio nas condições de Acorizal-MT. O experimento foi conduzido com mudas micropropagadas e aclimatadas das cultivares Brasão, Bruma, Eidibel, Juréia, Poiares, Sonata e Supremo, adquiridas de empresa idônea conveniada com o Instituto Agronômico de Campinas, com cerca de 0,1 m de altura. O substrato utilizado foi preparado com bagaço de cana-de-açúcar, palha de arroz, terra preta e esterco de bovino na proporção de 2:2:1:1. As mudas foram plantadas em janeiro de 2011 em quatro canteiros com cinco repetições de quatro plantas, totalizando 80 plantas por cultivar, em espaçamento de 0,3 x $0,3 \mathrm{~m}$. Os canteiros foram preparados em local sob malha preta com $80 \%$ de sombreamento O sistema de irrigação utilizado foi a microaspersão invertida, para manter o ambiente sempre úmido. As avaliações foram realizadas a partir do início da floração, de outubro de 2011 até janeiro de 2013. As inflorescências foram colhidas quando a espádice apresentava metade a três quartos das flores verdadeiras abertas. As avaliações foram do número e características (comprimento e largura da espata e, comprimento da espádice) das hastes florais. A cada dois meses realizou-se a reposição de cobertura dos canteiros com bagaço de cana. As cultivares Eidibel e Supremo foram as mais produtivas com 2,4 hastes/mês/planta; o maior tamanho da espata foi obtido pela cultivar Brasão com 17,2 cm de comprimento e 12,6 cm de largura; e a cultivar Sonata apresentou a maior espádice com 7,6 cm. As sete cultivares de antúrio, como flor de corte desenvolvem e florescem de maneira satisfatória.
\end{abstract}

Palavras-chave: flor tropical; potencial produtivo; haste floral.

\begin{abstract}
Production of cultivars of Anthurium andraeanum in Acorizal-MT conditions

The tropic flowers cultivation constitutes a niche market to be explored in the Mato Grosso state. The aim of this this work was evaluate the production of seven cultivars of anthurium in the conditions of Acorizal-MT. The experiment was conducted with micropropagated and acclimated seedlings of the cultivars Brasão, Bruma, Eidibel, Juréia, Poiares, Sonata e Supremo acquired from a reputable company associated with Campinas Agronomic Institute, with about $0,1 \mathrm{~m}$ of height. The substrate was prepared with sugarcane bagasse, rice straw, black soil and cattle manure in the ratio of 2:2:1:1. The seedlings were planted in January 2011, in four beds with five repetitions of four plants, totaling 80 plants of each cultivar, with $0,3 \times 0,3 \mathrm{~m}$ spacing. The beds were prepared on a place under black mesh with $80 \%$ shade. The irrigation system used was inverted microaspersion, to keep the environment always humid. The evaluations were performed from the beginning of flowering, from October 2011 until January 2013. Inflorescences were harvested when the spadix presented half to three quarters of the real flowers opened. Were evaluated the number and characteristics (length and width of the spathe and length of the spadix) of the flower stalks. Every two months there was a replacement in the bed's cover with sugarcane bagasse. The cultivars Eidibel and Supremo were the most productive with 2,4 stalks/month/plant; the bigger spathe was obtained by the cultivar Brasão with $17,2 \mathrm{~cm}$ of width and 12,6 cm length; and the cultivar Sonata presents the bigger spadix with $7,6 \mathrm{~cm}$. The seven cultivars of anthurium, as a cut flower, develop and bloom satisfactorily.
\end{abstract}

Keywords: tropical flower; productive potential; floral stem.

\section{INTRODUÇÃO}

A floricultura é um dos segmentos da agricultura de maior rentabilidade por unidade de área e proporciona um rápido retorno dos investimentos aplicados. O setor é altamente competitivo, exige a utilização de tecnologias avançadas e eficiência de distribuição e comercialização. Neste contexto, o Brasil se destaca pela expansão do cultivo de flores e folhagens tropicais, tanto para corte, quanto para produção de mudas.

Dentre as espécies tropicais importantes para floricultura brasileira, destaca-se o antúrio (Anthurium andraeanum Lind.), que é uma monocotiledônea originária da Colômbia, pertencente à família Araceae (COLLETTE et al., 2004), cuja haste floral comercializável é um conjunto formado por uma folha modificada, colorida (espata) e uma inflorescência tipo espiga (espádice), onde estão agregadas dezenas de pequenas flores verdadeiras (TOMBOLATO et al., 2004).

$\mathrm{O}$ antúrio é uma planta perene que exige condições de calor, umidade e sombra, ocorrendo em florestas tropicais úmidas (COLLETTE et al., 2004; DUFOUR e GUÉRIN,

\footnotetext{
(1) Trabalho recebido para publicação em 08/12/2013 e aprovado em 30/07/2014

(2) Doutora pelo Programa de Pós-graduação em Agricultura Tropical, Universidade Federal de Mato Grosso, Faculdade de Agronomia, Medicina Veterinária e

Zootecnia, email: clfava@superig.com.br

(3) Universidade Federal de Mato Grosso, Faculdade de Agronomia, Medicina Veterinária e Zootecnia, Departamento de Fitotecnia e Fitossanidade, Av.

Fernando Corrêa da Costa, nº 2367 - Bairro Boa Esperança. Cuiabá - MT - 78060-900, Brasil. E-mail: eccamili@hotmail.com
} 
2003). Seu desenvolvimento compreende duas fases distintas, a primeira corresponde à fase juvenil monopodial, e a segunda, à fase reprodutiva simpodial, durante a qual uma inflorescência é produzida em cada axila da folha (HIGAKI et al., 1984), mantendo a sequência folha e inflorescência, folha e inflorescência durante todo o ciclo de vida da planta, dependendo das condições do ambiente e nutricionais (TOMBOLATO et al., 2004).

A criação de condições microclimáticas adequadas para as culturas no interior dos ambientes protegidos pode ser obtida por meio de diversas técnicas, onde as mais econômicas são aquelas nas quais se empregam o uso e a combinação de diferentes tipos de material de cobertura (GUISELINI et al., 2010). A necessidade do uso de sombreamento na cultura decorre do fato de o antúrio ser uma planta de sombra no habitat natural e, quando exposta ao excesso de luz, apresenta folhas e inflorescências danificadas, o que pode levar até mesmo à morte da planta. O cultivo deve ser feito em locais protegidos dos raios solares diretos, variando o grau de sombreamento, conforme a idade das plantas e as condições climáticas predominantes no local, sobretudo temperatura e luz. Por isso, recomenda-se o uso de 70 a $80 \%$ de sombreamento (OMAR et al., 2004).

O antúrio adapta-se a uma grande faixa de temperatura (LAMAS, 2001). Contudo, a origem tropical do antúrio lhe confere melhor adaptação a regiões onde a temperatura mínima noturna se mantenha acima de $18{ }^{\circ} \mathrm{C}$ e a máxima diurna não ultrapassem $35{ }^{\circ} \mathrm{C}$ (TOMBOLATO et al., 2002), sendo que a temperatura diurna ideal situa-se entre 20 e 28 ${ }^{\circ} \mathrm{C}$. Temperaturas baixas retardam o desenvolvimento das plantas e diminuem seu florescimento, enquanto temperaturas elevadas em períodos de alta umidade relativa do ar favorecem o florescimento.

No cultivo comercial de antúrio, a utilização de plantas oriundas de cultura de tecidos é fundamental para que se tenha, além de produtividade alta, a uniformidade de plantas e flores, o que permitirá a classificação do produto conforme as exigências nacionais e internacionais.
Pelo interesse crescente na produção de flores tropicais, existe atualmente grande demanda por informações sobre o sistema de cultivo, nas mais diferentes regiões produtoras, sendo necessárias pesquisas para a definição de parâmetros de produção. Conhecer as exigências das diferentes espécies e cultivares é fundamental, para o sucesso da produção. Estudos nesse sentido auxiliarão a tomada de decisão do produtor em adequar ou não suas estruturas produtivas, visando o manejo que possibilite a maximização da produção.

Portanto, o objetivo neste trabalho foi avaliar o desenvolvimento de sete cultivares de antúrio como flor de corte nas condições de Acorizal-MT.

\section{MATERIAL E MÉTODOS}

A pesquisa foi realizada na área experimental da Empresa Mato-grossense de Pesquisa, Assistência e Extensão Rural (EMPAER-MT), no município de Acorizal, estado de Mato Grosso (22 $42^{\prime} 40^{\prime \prime} \mathrm{S}, 4^{\circ} 37^{\prime} 30^{\prime \prime} \mathrm{W}$ e $546 \mathrm{~m}$ ). O clima da região, segundo a classificação de Köppen é AW, denominado tropical úmido com seca no inverno (PEREIRA et al., 2002).

O material vegetal consistiu em mudas micropropagadas e aclimatadas, de sete cultivares, adquiridas de empresa idônea conveniada com o Instituto Agronômico de Campinas. $\mathrm{Na}$ ocasião do plantio, as plântulas apresentavam cerca de $0,10 \mathrm{~m}$ de altura. O plantio foi realizado em janeiro de 2011, em quatro canteiros confeccionados com blocos de cimento, sendo as dimensões de cada canteiro de 1,2 x 13,0 x 0,2 m, em viveiro com estrutura metálica com três metros de altura e coberto com malha preta que proporcionou $80 \%$ de sombreamento.

O substrato utilizado no enchimento dos canteiros foi composto por bagaço de cana-de-açúcar, casca de arroz, terra preta e esterco de bovino na proporção de 2:2:1:1. Após a mistura, a amostra foi coletada e enviada ao laboratório de análises de solo para avaliação da fertilidade do substrato (Tabela 1). A cada dois meses realizou-se a reposição da cobertura dos canteiros com bagaço de cana até o segundo ano de plantio, sem a necessidade de adubação química de cobertura.

Tabela 1. Resultado da análise química do substrato usado para a produção de cultivares de Anthurium andraeanum. Table 1. Results of the chemical analysis of substrate used for the production of cultivars Anthurium andraeanum.

\begin{tabular}{cccccc}
\hline \multirow{3}{*}{ Substrato } & $\mathrm{N}$ & $\mathrm{P}$ & $\mathrm{K}$ & $\mathrm{S}$ & $\mathrm{Ca}$ \\
\cline { 2 - 6 } & \multicolumn{5}{c}{$\mathrm{mg} \mathrm{dm}^{-3}$} \\
\cline { 2 - 6 } & 1,26 & 0,57 & 0,46 & 2,0 & 0,90 \\
\hline
\end{tabular}

As sete cultivares de antúrio avaliados foram: Brasão, Bruma, Eidibel, Juréia, Poiares, Sonata e Supremo, nos quatro canteiros com cinco repetições de quatro plantas, totalizando 80 plantas por cultivar espaçadas de $0,3 \times 0,3 \mathrm{~m}$.

O sistema de irrigação utilizado foi a microaspersão invertida, para manter o ambiente sempre úmido. As temperaturas e umidade mínimas e máximas foram monitoradas diariamente com auxílio de um termohigrometro.

As avaliações foram realizadas semanalmente a partir do início da floração, de outubro de 2011 a janeiro de 2013. As inflorescências foram colhidas quando a espádice apresentava metade a três quartos das flores verdadeiras abertas. Os parâmetros avaliados foram comprimento da haste floral, da emissão até a inserção da espata; comprimento e largura da espata, tomados na porção central das espatas e; comprimento da espádice, com uso de régua graduada, em centímetros.

Os resultados obtidos foram submetidos à análise estatística descritiva obtendo-se a média e desvio padrão para cada característica analisada.

\section{RESULTADOS E DISCUSSÃO}

A média mensal de temperatura máxima diária obtida foi de $40{ }^{\circ} \mathrm{C}$ em maio de 2012 , acima do recomendado por TOMBOLATO et al. (2004), para o cultivo de antúrio que é de $35^{\circ} \mathrm{C}$. Quanto à média mensal de temperatura mínima, obteve- 
se o valor de $15,8{ }^{\circ} \mathrm{C}$ em agosto de 2011 , abaixo do limite de temperatura mínima noturna recomendada pelo mesmo autor, $18{ }^{\circ} \mathrm{C}$, porém, esse comportamento climático já era esperado para o município de Acorizal/MT, e não trouxe prejuízos ao cultivo das plantas (Figura 1).

TOMBOLATO et al. (2004) recomendaram que a umidade relativa do ar seja superior a $50 \%$ para o cultivo de antúrio, no entanto, foi verificado que no mês de maio de 2011, no ambiente de produção deste trabalho, a umidade média ficou abaixo do recomendado (17\%), porém, esta não foi a realidade para a maioria dos meses, onde a média foi superior a $50 \%$ (Figura 2).

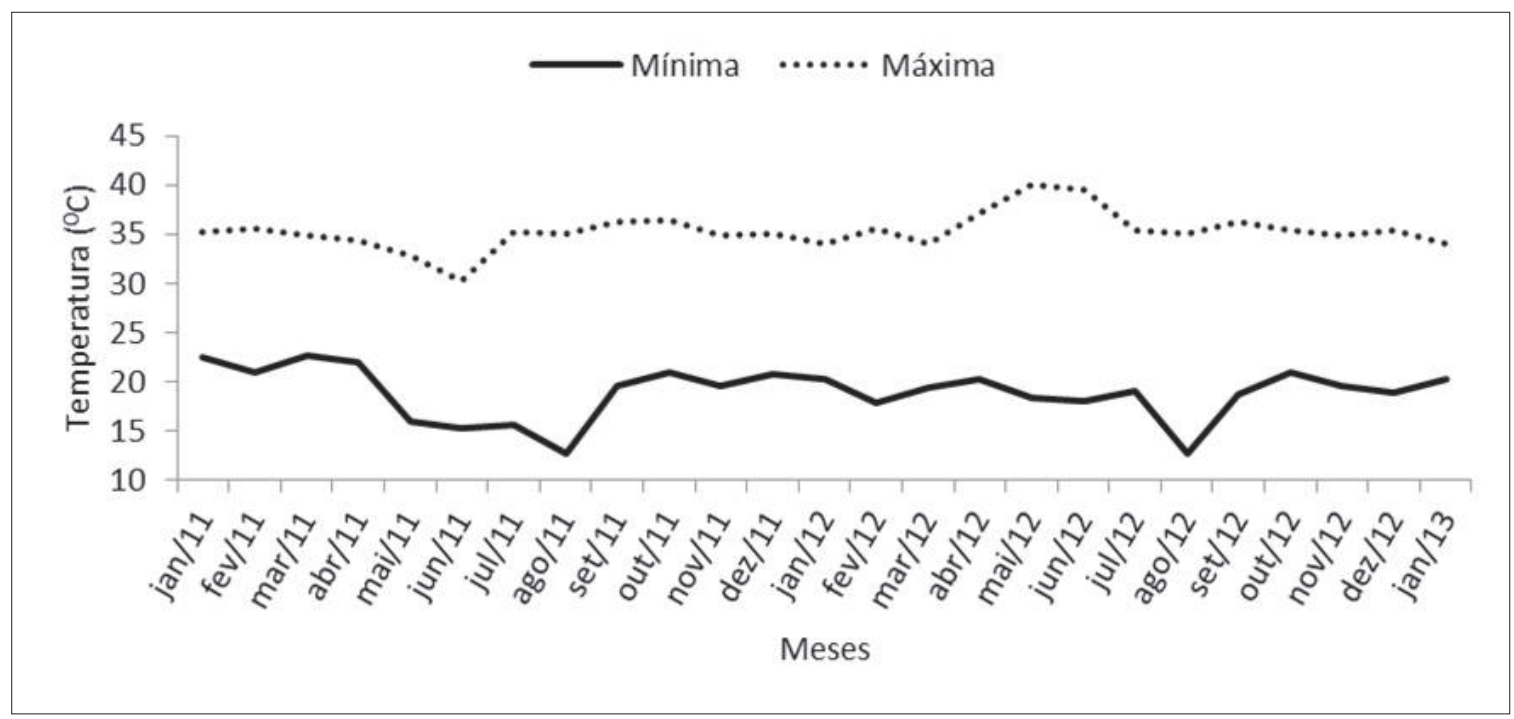

Figura 1. Média mensal das temperaturas máxima e mínima $\left({ }^{\circ} \mathrm{C}\right)$, no período de avaliação das cultivares de Anthurium andraeanum.

Figure 1. Average of the monthly maximal and minimal (oC) temperatures, in the period of evaluation of the cultivation of Anthurium andraeanum

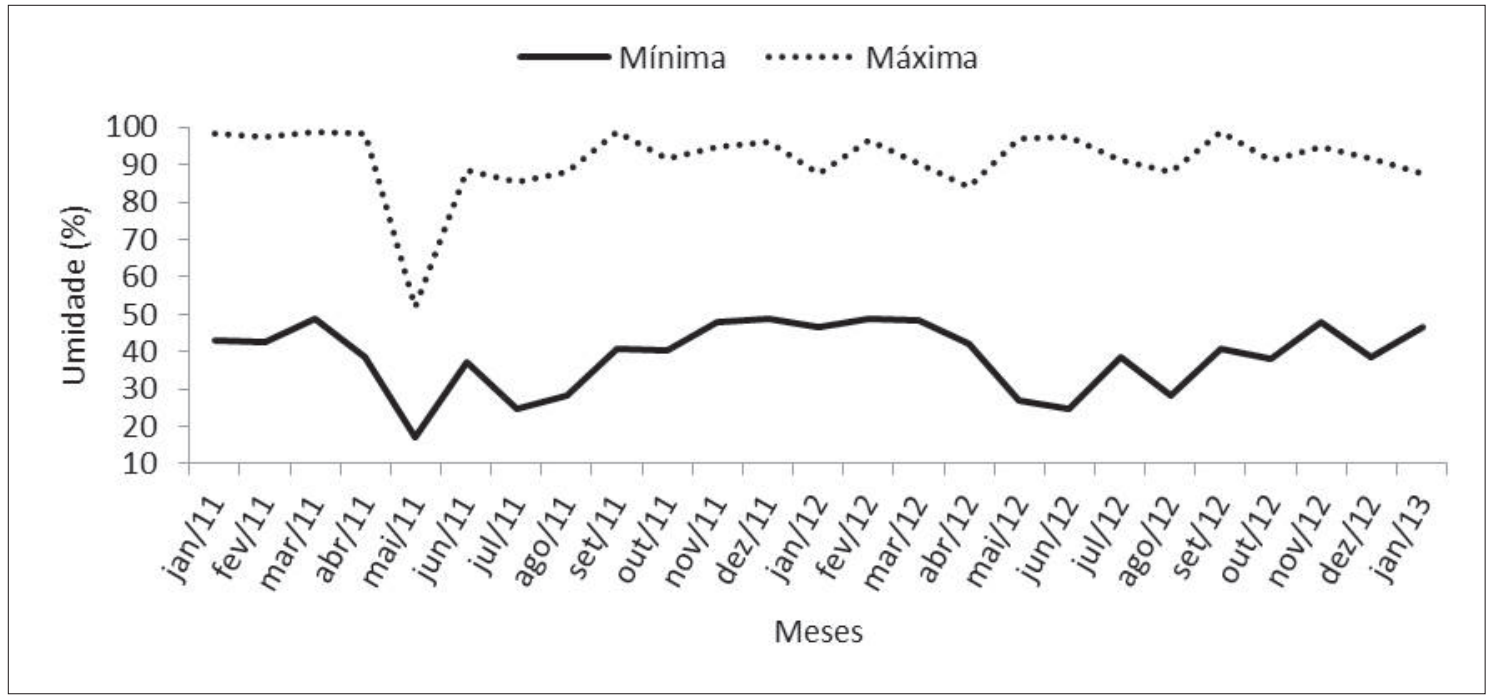

Figura 2. Média mensal da umidade máxima e mínima (\%), no período de avaliação das cultivares de Anthurium andraeanum.

Figure 2. Monthly average of maximal and minimum humidity (\%) during the period evaluation of the cultivation of Anthurium andraeanum.

O início do florescimento foi observado primeiro na cultivar Supremo, no $4^{\circ}$ mês de cultivo, porém, as espatas não foram avaliadas por se apresentarem minúsculas e fechadas, dificultando a avaliação. Somente a partir de outubro/2011, portanto, no $9^{\circ}$ mês, iniciaram-se as avaliações com as espatas de todos as cultivares totalmente abertos (Figura 3). LEME (2008) relatou que o início da produção da cultivar Eidibel em sistema hidropônico com fibra de coco ocorreu no $9^{\circ}$ mês, resultado semelhante ao encontrado com o cultivo tradicional em condições de Mato Grosso, o que é interessante porque a Eidibel é a cultivar brasileiro de maior destaque em relação às demais por seu formato, cor e brilho, e é a mais cultivada no Brasil (LEME, 2008). Em outra pesquisa, com cultivo realizado no município de Guaratuba (PR) foi verificado que a produção de espatas pelas cultivares Eidibel, Rubi, Juréia, Netuno, Iguape e Luau ocorreu, aproximadamente, 30 meses 
Tabela 2. Média de comprimento da haste floral, comprimento e largura das espatas e comprimento da espádice de sete cultivares de Anthurium andraeanum.

Table 2. Average flower stem length, length and width of spathes and spadix length of the seven cultivars of Anthurium andraeanum.

\begin{tabular}{|c|c|c|c|c|c|c|c|c|}
\hline Cultivares & C. da haste & DP & C. da espata & $\mathrm{DP}$ & L. da espata & $\mathrm{DP}$ & C. da espádice & DP \\
\hline & \multicolumn{8}{|c|}{ ㄱ... } \\
\hline Brasão & 61,4 & 38,6 & 17,2 & 6,8 & 12,6 & 7,1 & 7,2 & 1,6 \\
\hline Bruma & 45,9 & 23,0 & 14,2 & 7,4 & 9,9 & 6,9 & 5,5 & 0,9 \\
\hline Eidibel & 45,0 & 31,8 & 9,7 & 5,0 & 7,9 & 3,2 & 5,8 & 3,9 \\
\hline Juréia & 47,3 & 9,9 & 12,9 & 3,0 & 10,3 & 2,5 & 7,3 & 5,5 \\
\hline Poiares & 35,5 & 10,5 & 10,1 & 2,7 & 8,3 & 2,1 & 5,9 & 2,3 \\
\hline Sonata & 42,7 & 9,2 & 12,4 & 8,9 & 10,3 & 5,1 & 7,6 & 3,2 \\
\hline Supremo & 27,4 & 7,8 & 8,4 & 2,1 & 7,0 & 5,2 & 4,6 & 1,1 \\
\hline
\end{tabular}

DP: Desvio Padrão; C: Comprimento; L: Largura

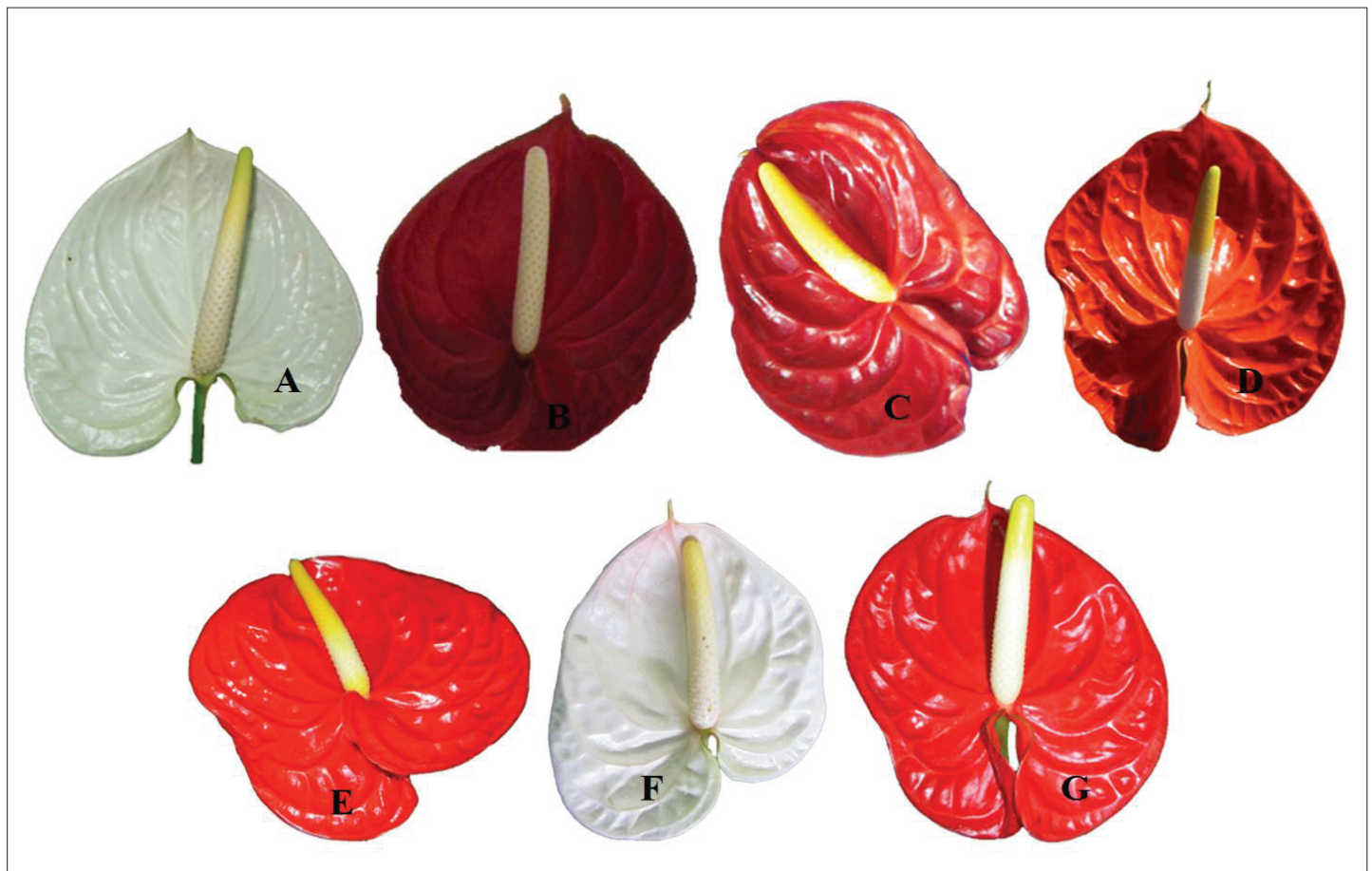

Figura 3. Espatas das cultivares de Anthurium andraeanum e as respectivas médias de comprimento: (A) Bruma (14,2 cm), (B) Brasão (17,2 cm), (C) Eidibel (9,7 cm), (D) Juréia (12,9 cm), (E) Poiares (10,0 cm), (F) Sonata (12,9 cm) e (G) Supremo (8,4 cm). Figure 3. Spathes cultivars of Anthurium andraeanum and the respective averages in length: (A) Bruma (14.2 cm), (B) Brasão $(17.2 \mathrm{~cm}),(C)$ Eidibel $(9.7 \mathrm{~cm}),(D)$ Juréia $(12.9 \mathrm{~cm})$ (E) Poiares $(10.0 \mathrm{~cm})$ (F) Sonata $(12.9 \mathrm{~cm})$ and $(G)$ Supremo $(8.4 \mathrm{~cm})$.

após o plantio das mudas (CUQUEL e GROSSI, 2004), período superior ao verificado com as cultivares Brasão, Bruma, Eidibel, Juréia, Poiares, Sonata e Supremo, em Acorizal-MT, que iniciaram a produção de hastes florais após nove meses do plantio.

As cultivares Eidibel e Supremo destacaram-se como as mais produtivas com 2,4 hastes/planta/mês, produzidas no mês de dezembro/2011 (11 meses após o plantio), e a com menor produção foi a cultivar Brasão com 0,1 hastes/ planta/mês, em abril/2012 (15 meses após o plantio) (Figura 4a), e a maior produção total de hastes florais foram para as cultivares Eidibel, Juréia e Sonata (Figura 4b).

No Ceará, PAIVA et al. (2004) observaram que a produção de plantas de antúrio oriundas de mudas com $5 \mathrm{~cm}$ de altura, cultivadas no solo após 18 meses do plantio foi em média de 2,91 espatas para a cultivar Cananéia; 2,84 para Astral; 2,1 para Isla; 2,0 para Iguape e 1,6 para Netuno, resultados esses, que foram equivalentes à média das cultivares produzidas em Acorizal-MT.

Os valores médios de comprimento da haste floral, largura e comprimento da espata e comprimento da espádice das cultivares de antúrio avaliadas em Acorizal/MT encontramse na Tabela 2. Na cultivar Supremo foram observados os menores valores de comprimento da haste floral com 27,4 $\mathrm{cm}$ e, Brasão foi a cultivar com a haste floral mais comprida, com $61,4 \mathrm{~cm}$. Embora o mercado consumidor de antúrio tenha preferência por hastes com comprimento mínimo de $60 \mathrm{~cm}$ (TOMBOLATO et al., 2004), esta característica foi verificada 


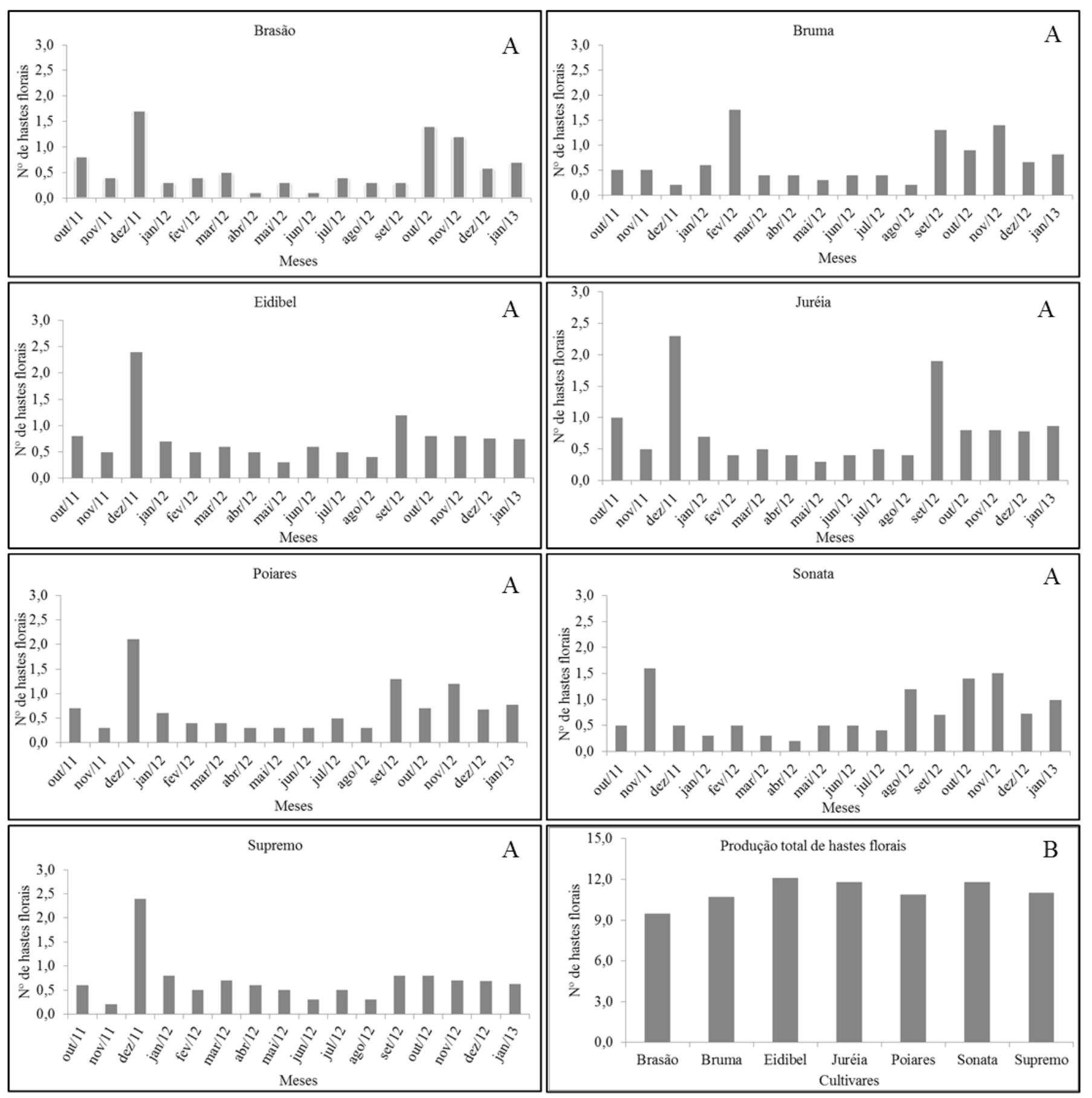

Figura 4. Média mensal (A) e produção total (B) de hastes florais/planta dos sete cultivares de Anthurium andraeanum nos dois primeiros anos após plantio.

Figure 4. Monthly average (A) and total production (B) of flower stalks/plant of the seven cultivars of Anthurium andraeanum in the first two years after planting.

com pouca frequência nas cultivares avaliadas. Este resultado pode ter sido influenciado pelo tempo de cultivo, onde a resposta das cultivares pode não ter sido imediata, ou seja, durante o período de avaliação, as plantas ainda não haviam expressado todo potencial de produção e não estavam ainda totalmente adaptadas às condições do ambiente de cultivo.

Em relação ao tamanho, comprimento e largura das espatas, os maiores valores foram obtidos pela cultivar Brasão; quanto às espádices, estas foram maiores na cultivar Sonata, e as menores espata e espádice foram produzidas pela cultivar Supremo (Tabela 2). TAKAHASHI et al. (2009) verificaram, em cultivo realizado no município de Londrina (PR), que os valores médios de largura e comprimento da espata e comprimento da espádice das cultivares Terena e Parakanã foram observadas nas hastes florais de menor tamanho (44,6 e 48,3 cm, respectivamente), diferindo das cultivares Rubi e Apalai, onde estes valores foram obtidos nas maiores hastes florais (53,6 e 51,6 cm, respectivamente).

Foi aplicada a classificação do comprimento das espatas, utilizada por LOGES et al. (2004) para flores de corte de antúrio produzidas no estado de Pernambuco, onde as cultivares melhoradas pelo IAC, as cultivares regionais e 
cultivares melhoradas (Anthura) são classificadas em três classes: pequena (menor que $8 \mathrm{~cm}$ ), média (entre 10 e $12 \mathrm{~cm}$ ) e grande (maior que $12 \mathrm{~cm}$ ). A referida classificação coloca na classe de tamanho médio as espatas das cultivares Supremo $(8,4 \mathrm{~cm})$, Eidibel $(9,7 \mathrm{~cm})$ e Poiares $(10,1 \mathrm{~cm})$ e na classe grande as cultivares Sonata $(12,4 \mathrm{~cm})$, Juréia $(12,9 \mathrm{~cm})$, Bruma (14,2 cm) e Brasão (17,2 cm).

\section{CONCLUSÃo}

As sete cultivares de antúrio, como flor de corte, desenvolvem e florescem de maneira satisfatória.

\section{AGRADECIMENTOS}

Os autores agradecem à Fundação de Amparo à Pesquisa do Estado de Mato Grosso pelo auxilio financeiro e a Empresa de Pesquisa Assistência e Extensão Rural/MT pela concessão da área para realização desse trabalho e pelo funcionário que incansavelmente nos auxiliou nesse período.

\section{REFERÊNCIAS}

COLLETTE, V.E.; JAMESON, P.E.; SCHWINN, K.E. ; UMAHARAN, P.; DAVIES, K.M. Temporal and spatial expression of flavonoid biosynthetic genes in flowers of Anthurium andraeanum. Physiologia Plantarum, v.122, n.3, p.297-304, 2004.

CUQUEL, F.L.; GROSSI, M.L. Produção de antúrio no litoral do Estado do Paraná. Revista Brasileira de Horticultura Ornamental, Campinas, v.10, n.1/2, p.35-37, 2004.

DUFOUR, L.; GUÉRIN, V. Growth, developmental features and flower production of Anthurium andreanum Lind. in tropical conditions. Scientia Horticulturae, Amsterdam, v.98, p.25-35, 2003.

GUISELINI, C.; SENTELHAS, P.C.; PANDORFI, H.; HOLCMAN, E. Manejo da cobertura de ambientes protegidos: Radiação solar e seus efeitos na produção da gérbera. Revista Brasileira de Engenharia Agrícola e Ambiental, Campina Grande, v.14, p.645-652, 2010.

HIGAKI, T.; RASMUSSEN, H.P.; CARPENTER W.J. A study of some orphological and anatomical aspects of Anthurium andreanum Lind. Honolulu: University of Hawaii, 1984. 12p. (HITAHR Research Series, 30).
LAMAS, A.M. Floricultura Tropical: Técnicas de Cultivo. Recife: SEBRAE/PE, 2001, 85 p.

LEME, J.M. Qualidade do antúrio 'IAC Eidibel' em cultivo hidropônico com fibra de coco. Campinas, SP. Universidade Estadual de Campinas, Faculdade de Engenharia Agrícola. 2008. 139p. Tese (Doutorado).

LOGES, V.; CASTRO, A.C.R.; TEIXEIRA, M.C.F; CASTRO, M.F.A. Experiências de cultivo de antúrio para flor de corte em Pernambuco. Revista Brasileira de Horticultura Ornamental, Campinas, v.10, n.1/2, p.38-41, 2004.

OMAR, M.H.; CHEONG, T.K.; HASHIM, N. For market access on anthurium. Kuala Lumpur, Malaysia: Crop Protection \& Plant Quarentine Services Division, Department of Agriculture, 2004. 44p. (Technical Document).

PAIVA, W.O.; CAVALCANTE, R.A.; BARROS, L.M. Melhoramento genético do antúrio no Ceará. Revista Brasileira de Horticultura Ornamental, Campinas, v.10, n.1/2, p.10-13, 2004.

PEREIRA, A.R.; ANGELOCCI, L.R.; SENTELHAS, P.C. Agrometeorologia: Fundamentos e aplicações práticas. Guaíba: Agropecuária, 2002. 478p.

TAKAHASHI, L.S.A.; FARIA, R.T.; TOMBOLATO, A.F.C.; CUQUEL, F.L.; GROSSI, M.L. Desenvolvimento de cultivares de antúrio IAC como plantas de vaso no Norte do Paraná. Bragantia, Campinas, v.68, n.3, p.593-600, 2009.

TOMBOLATO, A.F.C.; FURLANI, P.R.; CASTRO, C.E.F.; MATTHES, L.A.F.; TAGLIACOZZO, G.M.D; SAES, L.A.; RIVAS, E.B.; COUTINHO, L.N.; BERGAMAN, E.C.; IMENES, S.L.; COSTA, A.M.M.; LEME, J.M. Antúrio (Anthurium andraeanum Lindl). In. TOMBOLATO, A.F.C. Cultivo Comercial de Plantas Ornamentais. Campinas: Instituto Agronômico, 2004. 211p.

TOMBOLATO, A.F.C.; RIVAS, E.B.; COUTINHO, L.N.; BERGAMAN, E.C.; IMENES, S.L.; FURLANI, P.R.; CASTRO, C.E.F.; MATTHES, L.A.F.; SAES, L.A.; COSTA, A.M.M.; TAGLIACOZZO, G.M.D.; LEME, J.M. O cultivo de antúrio: produção comercial. Campinas: Instituto Agronômico, 2002. 47p. (Série Tecnologia APTA, Boletim técnico IAC, 194). 